\title{
1,2-Functionalized Imidazoles as Palladium Ligands: Efficient and Robust Catalytic System for the Fluorine-Free Hiyama Reaction
}

\author{
Regina Martínez, ${ }^{[a]}$ Isidro M. Pastor* ${ }^{[a]}$ and Miguel Yus* ${ }^{[a]}$
}

Dedicated to Professor Fernando Albericio on the occasion of his 60th birthday

Keywords: Palladium / Organosilane / Hiyama reaction / Imidazole / Cross-coupling

\begin{abstract}
A variety of hydroxy- and amino-functionalized imidazoles were prepared, from 1-methyl- and 1-(diethoxymethyl)imidazole, by means of isoprene mediated lithiation followed by reaction with an electrophile. These compounds in combination with palladium acetate were screened as catalyst for the Hiyama reaction under fluorine-free conditions using microwave irradiation. The systematic study of the catalytic system has proved $\mathbf{L} \mathbf{1}$ as the best ligand to be employed under solvent free conditions, and with a 1:2 ratio $\mathrm{Pd} /$ Ligand using also TBAB (20 mol-\%) as additive.
\end{abstract}

The study has revealed an interaction between the ratio Pd/Ligand and the amount of TBAB. The established catalytic system presented certain robustness, and it has been successfully employed in the coupling of different aryl bromides and chlorides with different aryl siloxanes. Furthermore, both reagents have been employed in an equimolecular amount, without an excess of organosilane. [a] Departamento de Química Orgánica, Facultad de Ciencias and Instituto de Síntesis Orgánica (ISO), Universidad de Alicante, Apdo. 99, 03080 Alicante, Spain

Fax: (+34)965903549

E-mail: ipastor@ua.es; yus@ua.es

Supporting information for this article is available on the WWW under http://dx.doi.org/10.1002/ejoc.xxxxxxxxx.

\section{Introduction}

The palladium catalyzed carbon-carbon bond formation between organosilicon reagents and organic halides, the Hiyama crosscoupling reaction, ${ }^{[1-3]}$ was first described in $1988 .{ }^{[4]}$ This type of transformation is really appealing due to the low toxicity, high stability and ease of handling of silicon reagents, albeit the strong carbon-silicon bond requires activation in order to suffer transmetalation. Thus, activation of the organosilicon compounds was successfully achieved by Hiyama's group employing fluoride ion, which produces the pentacoordinate silicon (the so-called hypervalent silanes) species necessary for the transmetalation step. ${ }^{[5]}$ Indeed, the electron density at silicon decreases with reduced s-character of the orbital combination, while the electron density at the silicon ligands is increased. ${ }^{[6]}$ This enhanced reactivity of pentacoordinated silicon is supported by calculations, which show the positive charge on the central silicon atom to be maintained, or even increased, by coordination of the fifth ligand. ${ }^{[7,8]}$ Regarding synthesis of unsymmetrical biaryls ${ }^{[9]}$ by means of Hiyama reaction, tetrabutylammonium triphenyldifluorosilicate was productively coupled with aryl iodides and aryl triflates in the presence of $\mathrm{Pd}(\mathrm{dba})_{2}$ catalyst in $1999 .{ }^{[10]}$ The scope of the reaction was next improved by the use of aryl siloxane derivatives as arylation reagents in the presence of fluoride ions as activating agent, and employing phosphine derivatives as ligands for the palladium. ${ }^{[11,12]}$ The next remarkable advance was the development of alternative methods to active the siloxane reagent, removing the use of the corrosive fluoride anions, as hydroxy anions. ${ }^{[13,14]}$ Later on, with the aim of increasing both reactivity and catalyst stability, a number of ligands have been developed and subsequently employed in the preparation of biary derivatives. ${ }^{[15]}$ For example, $N$-heterocyclic carbenes (NHC) were employed as palladium ligands both in the presence of fluoride or hydroxy anions ${ }^{[16-20]}$ and pincer-type palladium catalysts were also used in neat water under both fluoride and base induced conditions. ${ }^{[21]}$ Hiyama reactions with oxime-derived palladacycles were carried out in aqueous sodium hydroxide $\mathrm{e}^{[22,23]}$ and palladium nanoparticles were reacted under aqueous fluoride-free conditions or fluoride induced conditions. ${ }^{[24,25]}$ The search for new effective and robust catalytic systems for the coupling of organosiloxanes with aryl halides is still a challenging objective. In this sense, 2functionalized imidazoles have been described in the preparation of transition metal complexes and their catalytic activity. ${ }^{[26-31]}$ We have been working in the preparation of 2-hydroxyalkyl- and 2aminoalkylimidazole derivatives, such as L1-L12 (Figure 1), starting from different 1-substituted imidazoles. ${ }^{[32,33]}$ Herein, we report in detail on the results obtained employing this collection of ligands in the palladium-catalyzed Hiyama reaction under microwave irradiation. ${ }^{[34]}$ 
<smiles>Cn1ccnc1C(Nc1ccccc1)c1ccc(Cl)cc1</smiles>

L1<smiles>Cn1ccnc1C(Nc1ccccc1)c1ccccc1</smiles>

L2<smiles>COc1ccc(C(Nc2ccccc2)c2nccn2C)cc1</smiles>

L3<smiles>Cn1ccnc1C(Nc1ccc(Cl)cc1)c1ccccc1</smiles>

L4<smiles>CCC(O)(CC)c1nccn1C</smiles>
L5<smiles>Cn1ccnc1C(O)(c1ccccc1)c1ccccc1</smiles>

L6<smiles>Cn1ccnc1C(O)(c1ccccc1)c1ccccc1</smiles>

L7<smiles>Cn1ccnc1C(O)C(C)(C)C</smiles>

L8<smiles>CCC(O)(CC)c1ncc[nH]1</smiles>

L9<smiles>CC(O)(c1ccccc1)c1ncc[nH]1</smiles>

L10<smiles>OC(c1ccccc1)c1ncc[nH]1</smiles>

L11<smiles>c1ccc(NC(c2ccccc2)c2ncc[nH]2)cc1</smiles>

L12

Figure 1. Imidazole derivatives L1-L12.

\section{Results and Discussion}

\section{Preparation of Functionalized Imidazoles}

The 2-functionalized imidazole derivatives were easily prepared using an isoprene mediated lithiation methodology, widely studied by our research group. On the basis of density functional calculations, the isoprene seems to act as a base, after being reduced by lithium metal, deprotonating the $\mathrm{C}-2$ in the imidazole derivative, and giving the corresponding 1,1-dimethylallyl radical. This allyl radical can be further reduced by the excess of lithium to produce an allyl anion which can proceed once more as a base. ${ }^{[35]}$ Therefore, commercially available 1-methylimidazole $\mathbf{1}$ was treated with lithium powder and isoprene (0.2 equiv.) in THF producing the corresponding 2-lithioimidazole intermediate, which subsequent reaction with an electrophile gave, after hydrolysis, the expected amino- and hydroxy-functionalized imidazoles L1-L8 (Scheme 1). ${ }^{[32]}$ In addition, we prepared 2-functionalized imidazoles L9-L12 starting from 1-(diethoxymethyl)imidazole 2, which was treated with an excess of lithium and isoprene (1 equiv.) followed by reaction with different electrophiles. The corresponding ligands L9-L12 were obtained after acidic treatment of the reaction mixture (Scheme 1). ${ }^{[33]}$ This simple synthetic strategy allowed us to obtain a variety of 12 imidazole derivatives, bearing different potential coordinating functional groups for the palladium metal center.
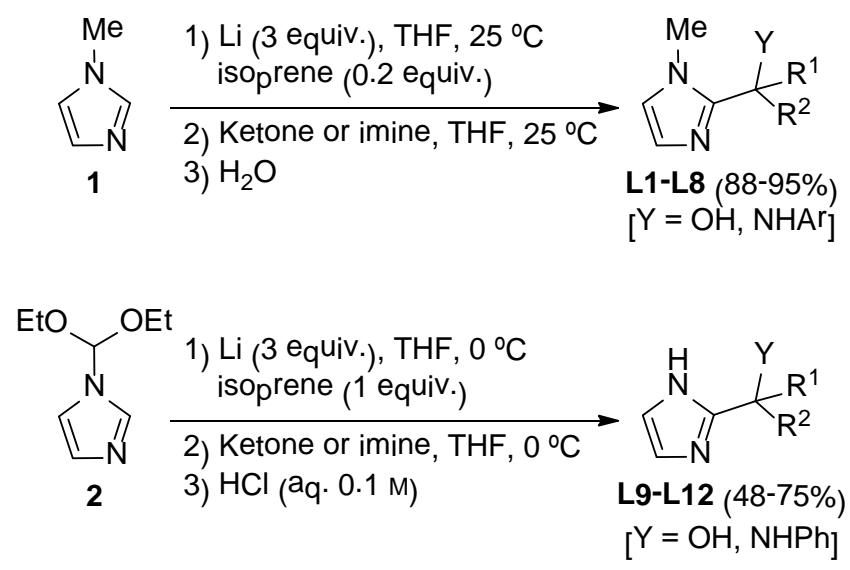

Scheme 1. Preparation of ligands L1-L12 by an isoprene mediated lithiation methodology.

\section{Ligand Screening}

The set of 12 ligands was evaluated in the coupling of 4bromoanisole with trimethoxy(phenyl)silane, under solvent free conditions and microwave irradiation. ${ }^{[19]}$ The reactions were carried out using $\mathrm{Pd}(\mathrm{OAc})_{2}$ (0.1 mol-\%), $\mathrm{NaOH}$ (solution, 50\% $\mathrm{w} / \mathrm{w}$ ), as source of hydroxide anion, and the reaction mixture was heated at $100{ }^{\circ} \mathrm{C}$ by a microwave irradiation of $80 \mathrm{~W}$ (initial power), during 30 minutes. The reactions were quenched and the yield was then analyzed by GLC, employing tridecane as internal standard. The results are summarized in Figure 2, which shows the yield of 4-methoxybiphenyl $\mathbf{3}$ as function of the ligand employed.

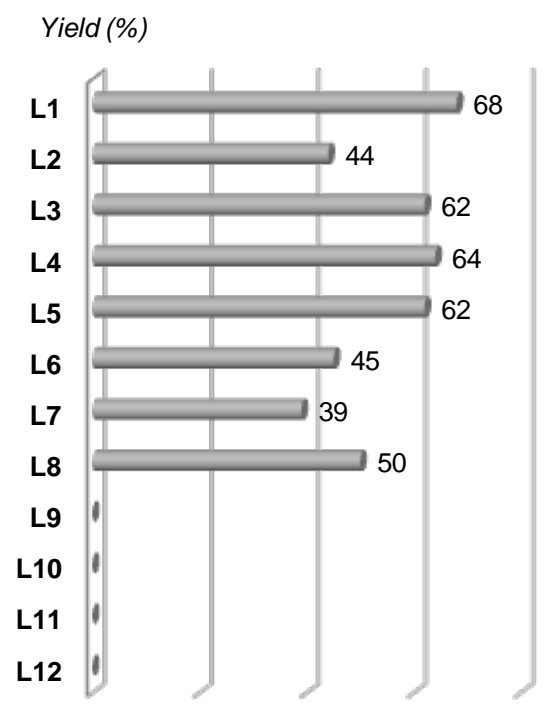

Figure 2. Yield of 4-methoxybiphenyl using ligands L1-L12.

From the plot in Figure 2 it is evident that the substituent in the nitrogen of the imidazole moiety is important for the activity of the palladium catalyst formed in situ. In general, comparing both 1methylimidazole series, amino-functionalized derivatives showed slightly higher activity than the corresponding hydroxyfunctionalized ones, albeit L5 gave similar level of activity (producing 4-methoxybiphenyl $\mathbf{3}$ in 62\% yield) than L1, L3 and L4 (62-68\% yield of 3). Consequently for further studies, we decided 
to continue with ligands $\mathbf{L} \mathbf{1}$ and $\mathbf{L} \mathbf{5}$ in order to keep both amino and hydroxy functionalities in the ligand structure. Additionally, it is worthy to mention that the use of both ligands is helpful for the catalytic reaction, since the reaction employing only $\mathrm{Pd}(\mathrm{OAc})_{2}$ as catalyst gave the product 3 with $42 \%$ yield.

\section{Optimization of the Parameters}

Our next aim was to optimize the process, employing a design of experiments (DOE) $)^{[36]}$ to plan a minimum set of assays to check a variety of parameters, and to obtain the maximum information about which would be the critical factors and the best combination of variables. The coupling between 4-bromoanisole and trimethoxy(phenyl)silane, in $1: 1$ molecular ratio, at $100{ }^{\circ} \mathrm{C}$ using microwave irradiation, ${ }^{[3]}$ for 30 minutes, was chosen as model reaction to be optimized. The DOE was performed for five parameters with 2 or 3 levels: (a) solvent (water, ethanol, solventfree conditions), (b) amount of palladium (0.1 and 0.5 mol-\%), (c) ligand (L1 and L5), (d) Pd/Ligand ratio (1:1, 1:2 and 1:5) and (e) the use or not of an additive such as tetrabutylammonium bromide (TBAB). The first set of experiments was selected according to a Taguchi L18 array (Table 1, entries 1-18). On the basis of this series of experiments, we prepared a new collection of experiments (Table 1, entries 19-28) in order to gain more information about this catalytic system.

Table 1. Optimization of Hiyama coupling reaction by microwave

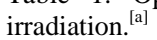
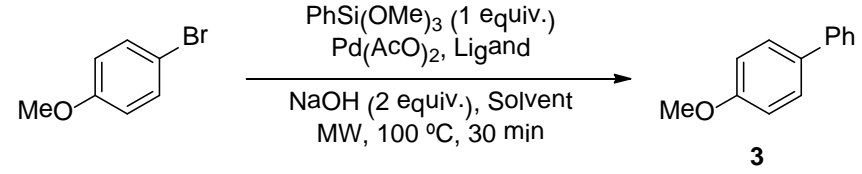

\begin{tabular}{|c|c|c|c|c|c|c|}
\hline Entry & Solvent & $\begin{array}{l}\mathrm{Pd}(\mathrm{OAc}) \\
2 \\
(\mathrm{~mol}-\%)\end{array}$ & $\begin{array}{l}\text { Ratio } \\
\text { Pd/Ligand }\end{array}$ & $\begin{array}{l}\text { ТВAB } \\
\text { (mol-\%) }\end{array}$ & Ligand & $\begin{array}{l}\text { Yield } \\
(\%)^{[b]}\end{array}$ \\
\hline 1 & Neat & 0.1 & $1: 2$ & 0 & L5 & 62 \\
\hline 2 & Neat & 0.1 & $1: 1$ & 0 & L5 & 54 \\
\hline 3 & Neat & 0.1 & $1: 2$ & 0 & L1 & 68 \\
\hline 4 & Neat & 0.1 & $1: 5$ & 0 & L5 & 23 \\
\hline 5 & Neat & 0.5 & $1: 2$ & 0 & L5 & 52 \\
\hline 6 & Water & 0.1 & $1: 2$ & 0 & L5 & 15 \\
\hline 7 & Water & 0.1 & $1: 2$ & 0 & L1 & 14 \\
\hline 8 & Water & 0.1 & $1: 5$ & 0 & L5 & 11 \\
\hline 9 & $\mathrm{EtOH}$ & 0.1 & $1: 2$ & 0 & L5 & 48 \\
\hline 10 & $\mathrm{EtOH}$ & 0.1 & $1: 2$ & 0 & L1 & 11 \\
\hline 11 & Neat & 0.1 & $1: 2$ & 20 & L5 & 70 \\
\hline 12 & Neat & 0.1 & $1: 1$ & 20 & L5 & 59 \\
\hline 13 & Water & 0.1 & $1: 2$ & 20 & L5 & 21 \\
\hline 14 & $\mathrm{EtOH}$ & 0.1 & $1: 2$ & 20 & L5 & 22 \\
\hline 15 & $\mathrm{EtOH}$ & 0.5 & $1: 1$ & 0 & L5 & 30 \\
\hline 16 & Neat & 0.1 & $1: 1$ & 20 & L1 & 78 \\
\hline 17 & Neat & 0.5 & $1: 1$ & 20 & L5 & 50 \\
\hline 18 & Neat & 0.1 & $1: 5$ & 0 & L1 & 78 \\
\hline 19 & Neat & 0.1 & $1: 1$ & 0 & L1 & 60 \\
\hline 20 & Neat & 0.5 & $1: 2$ & 0 & L1 & 60 \\
\hline 21 & Neat & 0.5 & $1: 1$ & 0 & L5 & 62 \\
\hline 22 & Neat & 0.5 & $1: 5$ & 0 & L5 & 16 \\
\hline
\end{tabular}

\begin{tabular}{lllllll}
23 & EtOH & 0.1 & $1: 1$ & 0 & L5 & 24 \\
24 & EtOH & 0.1 & $1: 5$ & 0 & $\mathbf{L 5}$ & 27 \\
25 & Neat & 0.5 & $1: 2$ & 0 & $\mathbf{L 1}$ & 73 \\
26 & Neat & 0.1 & $1: 2$ & 20 & $\mathbf{L 1}$ & 89 \\
27 & Neat & 0.5 & $1: 2$ & 20 & $\mathbf{L 1}$ & 79 \\
28 & Neat & 0.1 & $1: 5$ & 20 & $\mathbf{L 1}$ & 74 \\
\hline [a] & Reaction & conditions: & 4-bromoanisole & $(0.5$ & mmol)
\end{tabular}
Reaction Conditions: 4-bromoanisole $\quad(0.5 \quad$ mmol $)$,
trimethoxy(phenyl)silane $(0.5 \mathrm{mmol}), \mathrm{NaOH}(1 \mathrm{mmol}), \mathrm{Pd}(\mathrm{OAc})_{2}(0.1$ or 0.5 mol-\%), Ligand (0.1 to 2.5 mol-\%), TBAB (0 or 20 mol-\%), solvent (1 $\mathrm{mL}$ ), $100{ }^{\circ} \mathrm{C}$ (initial power of $80 \mathrm{~W}$ ), $30 \mathrm{~min}$. [b] The yield was calculated by GLC analysis employing tridecane as internal standard.

The reaction gives better yield when performed under solvent free conditions (see Supporting Information), and using the amino functionalized imidazole $\mathbf{L} \mathbf{1}$ as ligand (see Supporting Information). The level of palladium resulted not to be a crucial factor, so we chose the lowest level of $0.1 \mathrm{~mol}-\%$ of palladium. The presence of TBAB (20 mol-\%) in the reaction mixture seems to increase the stability of the catalytic system, increasing the yield of the reaction (see Supporting Information). However, the additive seemed to interact with the ratio $\mathrm{Pd} /$ Ligand parameter, so we decided to explore a bit more in detail this possible interaction.

Accordingly, both parameters were considered in 3 levels $(0,20$ and $50 \mathrm{~mol}-\%$ for TBAB, and 1:1, 1:2 and 1:5 for $\mathrm{Pd} / \mathbf{L} \mathbf{1}$ ratio) in order to conduct a new set of experiments, following a $3^{2}$ factorial design. The results are graphed in Figure 3 and, as anticipated, an interaction was found, ${ }^{[38]}$ the proper combination of both parameters being significant for the best outcome of the reaction. Interestingly, the higher the amount of $\mathbf{L 1}$ the better when the additive is used in 50 mol-\% (high level), but the lower the amount of $\mathbf{L} \mathbf{1}$ the better when TBAB is not used (low level). Furthermore, for the medium level of TBAB (20 mol-\%), the behaviour is not linear with a maximum for the Pd/Ligand ratio 1:2. Actually, comparing the levels of 0 and $20 \mathrm{~mol}-\%$ of TBAB, there is no interaction when using high amount of ligand (ratio from 1:2 to 1:5), but there is for low amounts of ligand. On the contrary, the interaction between the parameters appears at high amounts of ligand when levels 20 and 50 mol-\% of TBAB are employed.

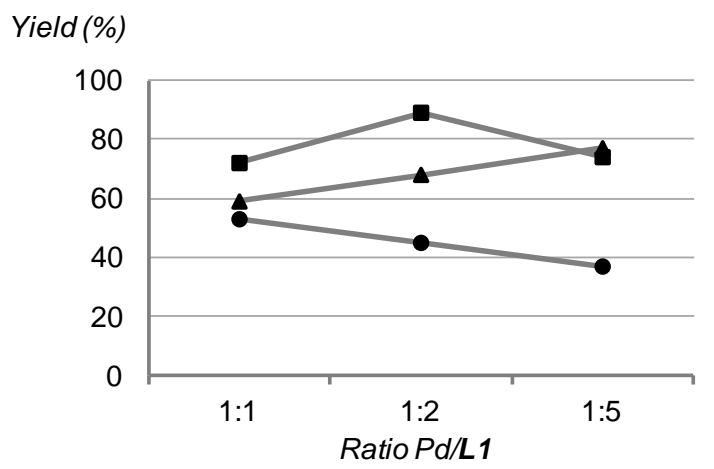

Figure 3. Interaction graph between ratio $\mathrm{Pd} / \mathbf{L 1}$ and the amount of TBAB:

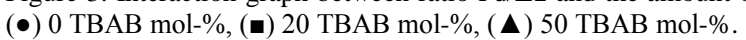




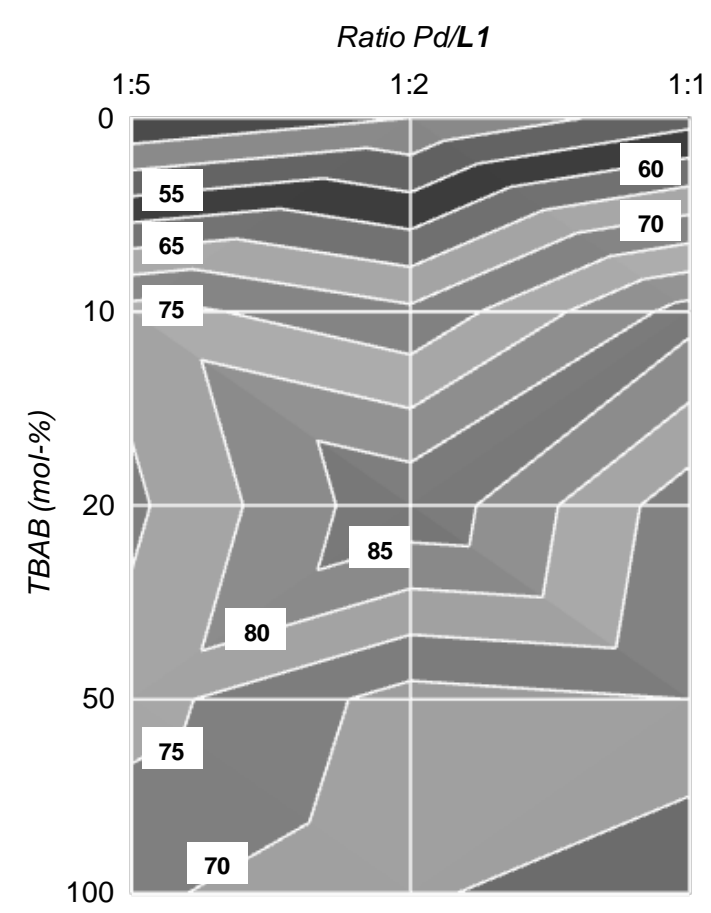

Figure 4. Contour map (\% yield of $\mathbf{3}$ ) as function of the two factors, amount of TBAB (mol-\%) and $\mathrm{Pd} / \mathbf{L} \mathbf{1}$ ratio.

The study was completed employing levels of 10 mol-\% and 100 mol-\% for TBAB together with the Pd/Ligand ratios 1:1, 1:2 and 1:5, finding an interesting behaviour. The contour map with all the results is depicted in Figure 4, and it can be observed that best conditions are around the point $20 \mathrm{~mol}-\%$ of TBAB and a ratio $1: 2$ for $\mathrm{Pd} /$ Ligand. Therefore, the product can be obtained in yield over $85 \%$ by keeping the reaction conditions within small variations around this point, what represents a robust catalytic system. Moreover, we realized that for higher amounts of TBAB, i.e. more than $50 \mathrm{~mol}-\%$, the $\mathrm{Pd} /$ Ligand ratio parameter is not determinant in the outcome of the reaction, and the yield is in the range of $70-75 \%$ independently of the $\mathrm{Pd} /$ Ligand ratio (Figure 6). In consequence, the proper choice of both factors considered in this study (i.e. 20 mol-\% of TBAB and a ratio 1:2 Pd/Ligand) has been demonstrated to be important. Additionally, there is certain robustness around these reaction conditions what makes this catalytic system more remarkable.

\section{Modeling the Interaction TBAB versus Pd/Ligand Ratio}

Design of experiment protocols allow further mathematical analyses. In order to get a better understanding of the nature of the designed space and map the curvature of the process, a study employing a response surface model was performed to complement the information obtained in the DOE. Figure $5 \mathrm{a}$ shows the calculated model (2FI = Two Factor Interaction Model) for the yield in a 3D surface graph (range of 0 to 20 mol- $\%$ of TBAB). The points for 0 mol- $\%$ of TBAB gave yields between 37 and $53 \%$ which were below the value predicted by the linear 2FI model, thus indicating significant curvature. a)
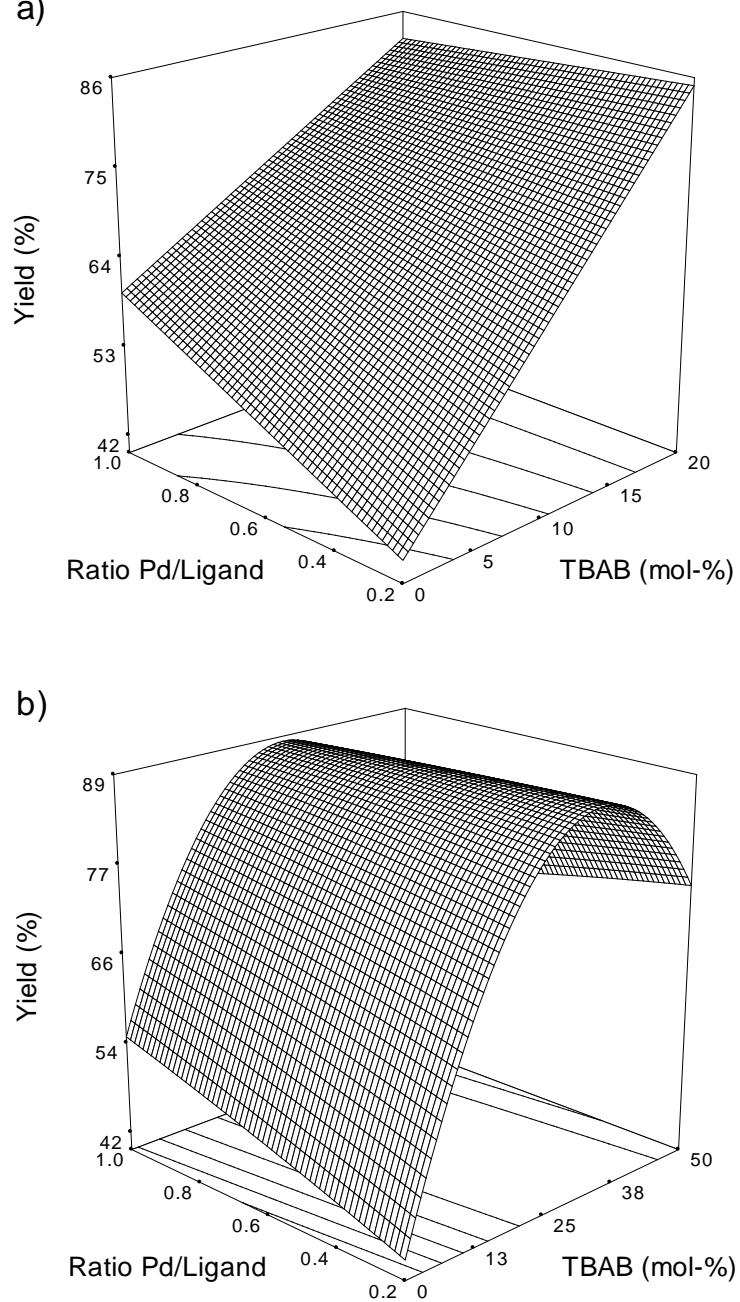

Figure 5. (a) Three dimensional view of the 2FI model for the different $\mathrm{Pd} /$ Ligand ratios in the range 0 to $20 \mathrm{~mol}-\%$ of TBAB; (b) Three dimensional view of the Quadratic model for the different Pd/Ligand ratios in the range 0 to $50 \mathrm{~mol}-\%$ of $\mathrm{TBAB}$.

Furthermore, taking into consideration the range from 0 to 50 mol- $\%$ of TBAB, a quadratic model was generated, and the yields at each reaction conditions can be visualized in the three dimension surface graph depicted in Figure 5b. This model demonstrates that the interaction of the two considered factors is important for the outcome of the reaction, the curvature being significant. This is clear indication that a linear model within 2FI is not descriptive of the real response surface when the study is extended to higher amounts of additive (TBAB). In any case, any model derived from this can only give a rough indication for point predictions within the chosen boundaries. In sight of the quadratic model for the yield as $3 \mathrm{D}$ surface graphic (Figure $5 \mathrm{~b}$ ), the amount of TBAB can be determined as the more important factor in the outcome of the reaction, followed by the proper selection of the ratio $\mathrm{Pd} /$ Ligand. The model gives indications regarding the best conditions, but it is clear that the optimum area to operate this reaction is wider than predicted around the 1:2 ratio, and for higher and lower ratios the predicted values by the quadratic model were above the experimental.

Scope of the Cross-Coupling Hiyama Reaction 
With the results from the ligand optimization described above, we continued with an examination of substrate scope for the synthesis of different biaryl derivatives. The ligand $\mathbf{L 1}$ in 0.2 mol$\%$ in combination with a $0.1 \mathrm{~mol}-\%$ of $\mathrm{Pd}(\mathrm{OAc})_{2}$ was employed in the presence of TBAB (20 mol-\%). ${ }^{[39]}$ The reactions were performed at $100{ }^{\circ} \mathrm{C}$ using microwave irradiation, ${ }^{[40]}$ during 30 minutes, and the aryl halides and siloxane reagents were employed in equimolecular amount. At this point it is worthy to mention that performing the reaction with higher amount of siloxane (1.5 equiv.) gave the same results.

As seen in Table 2, the coupling of aryl bromides, bearing different electron-donating and electron-withdrawing groups, with trimethoxy(phenyl)silane produced the expected biaryls 3-7 with isolated yields ranging from 78 to $89 \%$ (Table 2, entries 1-5), what makes extensive the robustness of the catalytic system to other substrates. In the case of more congested 2-bromotoluene, similar yield (85\%) of the coupling product 8 was obtained (Table 2, entry 6 ), whereas the 2-bromophenol was coupled with moderate yield (Table 2, entry 7). A plausible explanation for the poor reactivity obtained with the latter substrate can be found in deactivation of the catalyst by substrate coordination. The reaction with heteroaryl halides usually is less efficient, but the reaction with 3bromopyridine using this reaction conditinos resulted in the formation of 3-phenylpyridine $\mathbf{1 0}$ with $\mathbf{8 0 \%}$ yield (Table 2, entry 8) On the other hand, 3-bromothiophene showed lower activity (Table 2, entry 9). Interestingly, the use of trimethoxy(4methylphenyl)silane, as coupling partner for aryl bromides, resulted in the formation of the corresponding biaryl compounds 12-15 with yields ranging from 71 to $82 \%$ (Table 2, entries 10-13), while the aryl siloxane bearing an electron-donating group [i.e. triethoxy(4-methoxyphenyl)silane] was less reactive under the same reaction conditions (Table 2, entries 14 and 15).

Finally, use of the catalyst in the cross-coupling reaction of aryl siloxane with the less reactive aryl chlorides resulted, certainly, in the formation of the expected biaryls with slightly lower yields compared with the previous substrates (Table 2, entries 16-18). 4Chlorotoluene reacted with trimethoxy(phenyl)silane yielding 4methyl-1,1'-biphenyl $\mathbf{1 8}$ in $69 \%$, and more activated 4chloroacetophenone yielded biaryl $\mathbf{6}$ in $79 \%$. The catalytic system was not effective enough when 3-chloropyridine was used, and compound $\mathbf{1 0}$ was obtained only with a $30 \%$ yield.

Table 2. Biaryl synthesis by Hiyama reaction with the catalytic system $\mathrm{Pd}(\mathrm{OAc})_{2} / \mathbf{L 1}^{\text {[a] }}$

$$
\mathrm{Ar}^{1}-\mathrm{X}+\mathrm{Ar}^{2}-\mathrm{Si}(\mathrm{OR})_{3} \underset{\mathrm{NaOH}(2 \text { equiv. }), \mathrm{MW}, 100^{\circ} \mathrm{C}, 30 \mathrm{~min}}{\stackrel{\mathrm{Pd}(\mathrm{ACO})_{2}(0.1 \mathrm{~mol}-\%), \mathrm{L1}(0.2 \mathrm{~mol} \%)}{\mathrm{N}}} \mathrm{Ar}^{1}-\mathrm{Ar}^{2}
$$

\begin{tabular}{|c|c|c|c|c|}
\hline Entry & Aryl halide & Aryl(trialkoxy)silane & Product & $\begin{array}{l}\text { Yield } \\
(\%)^{[b]}\end{array}$ \\
\hline 1 & $4-\mathrm{MeOC}_{6} \mathrm{H}_{4} \mathrm{Br}$ & $\mathrm{PhSi}(\mathrm{OMe})_{3}$ & 3 & 89 \\
\hline 2 & $4-\mathrm{HOC}_{6} \mathrm{H}_{4} \mathrm{Br}$ & $\mathrm{PhSi}(\mathrm{OMe})_{3}$ & 4 & 78 \\
\hline 3 & $4-\left(\mathrm{NO}_{2}\right) \mathrm{C}_{6} \mathrm{H}_{4} \mathrm{Br}$ & $\mathrm{PhSi}(\mathrm{OMe})_{3}$ & 5 & 86 \\
\hline 4 & 4-(MeCO) $\mathrm{C}_{6} \mathrm{H}_{4} \mathrm{Br}$ & $\mathrm{PhSi}(\mathrm{OMe})_{3}$ & 6 & 89 \\
\hline 5 & $4-t-\mathrm{BuC}_{6} \mathrm{H}_{4} \mathrm{Br}$ & $\mathrm{PhSi}(\mathrm{OMe})_{3}$ & 7 & 82 \\
\hline 6 & $2-\mathrm{MeC}_{6} \mathrm{H}_{4} \mathrm{Br}$ & $\mathrm{PhSi}(\mathrm{OMe})_{3}$ & 8 & 85 \\
\hline 7 & $2-\mathrm{HOC}_{6} \mathrm{H}_{4} \mathrm{Br}$ & $\mathrm{PhSi}(\mathrm{OMe})_{3}$ & 9 & 40 \\
\hline 8 & 3-Bromopyridine & $\mathrm{PhSi}(\mathrm{OMe})_{3}$ & 10 & 80 \\
\hline 9 & 3-Bromothiophene & $\mathrm{PhSi}(\mathrm{OMe})_{3}$ & 11 & 44 \\
\hline 10 & 4- $\mathrm{MeOC}_{6} \mathrm{H}_{4} \mathrm{Br}$ & $4-\mathrm{MeC}_{6} \mathrm{H}_{4} \mathrm{Si}(\mathrm{OMe})_{3}$ & 12 & 78 \\
\hline 11 & $4-t-\mathrm{BuC}_{6} \mathrm{H}_{4} \mathrm{Br}$ & $4-\mathrm{MeC}_{6} \mathrm{H}_{4} \mathrm{Si}(\mathrm{OMe})_{3}$ & 13 & 80 \\
\hline
\end{tabular}

82

[a] Reaction conditions: aryl halide (2 mmol), aryl(trialkoxy)silane (2 mmol), $\mathrm{NaOH}$ (2 equiv., $50 \%$ aqueous solution), $\mathrm{Pd}(\mathrm{OAc})_{2}(0.1 \mathrm{~mol}-\%)$, L1 (0.2 mol-\%), TBAB (20 mol-\%), $100{ }^{\circ} \mathrm{C}$ (initial power of $80 \mathrm{~W}$ ) for 30 min. [b] Isolated yield of pure product after purification by flash chromatography (silica gel; hexane/ethyl acetate mixtures), or recrystallization.

\section{Conclusions}

We have demonstrated that amino- and hydroxy-functionalized 1-methylimidazoles, function as efficient ligands for the palladium catalyzed Hiyama reaction. The ligands were easily prepared by isoprene mediated lithiation methodology followed by reaction with a carbonyl compound or an imine. When combined with palladium acetate the catalytic system formed in situ promotes the fluorine-free Hiyama reaction under solvent free conditions using microwave irradiation. The utilization of Design of Experiments protocols has allowed for the examination of multiple variables simultaneously and facilitated formulation reaction conditions for aryl bromides. The information derived from the systematic study revealed an interaction between both factors, the amount of additive and the $\mathrm{Pd} /$ Ligand ratio. Palladium/ligand $\mathbf{L} 1$ in ratio 1:2 together with 20 mol-\% of TBAB as additive were determined as the best catalytic system. The resulting process represented a robust procedure capable of operating with a variety of aryl siloxanes and aryl bromides and chlorides in the preparation of biaryl derivatives.

\section{Experimental Section}

General remarks. All commercially available reagents (Acros, Aldrich, Fluka) wer used without further purification. Melting points were determined with a Reichert Thermovar hot plate apparatus and are uncorrected. NMR spectra were recorded on a Bruker-Avance 300 and a Bruker-Avance 400 (300 and $400 \mathrm{MHz}$ for ${ }^{1} \mathrm{H}-\mathrm{NMR}$ and 75 and $100 \mathrm{MHz}$ for ${ }^{13} \mathrm{C}$-NMR) using, except otherwise stated, $\mathrm{CDCl}_{3}$ as solvent and TMS as internal standard; chemical shifts are given in $\delta$ (ppm) and coupling constants $(J)$ in Hertz. Mass spectra (EI) were obtained at $70 \mathrm{eV}$ on an Agilent 5973 spectrometer, fragment ions in $\mathrm{m} / \mathrm{z}$ with relative intensities (\%) in parenthesis. Infrared spectra were recorded on a Perkin-Elmer Spectrum 100 spectrometer as neat solids. Analytical TLC was performed on Merck aluminum sheets with silica gel 60 F254. Silica gel 60, (0.004$0.06 \mathrm{~mm}$ ) was employed for flash chromatography. Microwave reactions were performed with a CEM Discover Synthesis Unit (CEM Corp., Matthews, NC) with a continuous focused microwave power delivery system in glass vessels $(10 \mathrm{~mL})$ sealed with a septum under magnetic stirring.

General procedure for the cross-coupling of aryl halides with siloxanes. A $10 \mathrm{~mL}$ MW vessel was charged with $\mathrm{Pd}(\mathrm{OAc})_{2}$ (0.002 mmol, $\left.0.4 \mathrm{mg}\right)$, ligand $\mathbf{L 1}$ (0.004 mmol, $0.8 \mathrm{mg}$ ), the aryl halide (2 $\mathrm{mmol})$, the organosilicon ( $2 \mathrm{mmol})$, and TBAB (0.2 mmol, $128 \mathrm{mg})$. Then, $0.2 \mathrm{~mL}$ of an aqueous solution of $\mathrm{NaOH}(50 \% \mathrm{w} / \mathrm{w})$ was added dropwise. The vessel was sealed with a septum and the mixture was heated in air at $100{ }^{\circ} \mathrm{C}$ by microwave irradiation of initial power of $80 \mathrm{~W}$ for $30 \mathrm{~min}$. After allowing 
the reaction to cool down to room temperature, it was extracted with ethyl acetate $(5 \times 5 \mathrm{~mL})$, and the combined organic layers were filtered through a pad of Celite and anhydrous $\mathrm{Mg}_{2} \mathrm{SO}_{4}$, and then evaporated. The obtained crude product was purified by recrystallization in $\mathrm{MeOH} / \mathrm{H}_{2} \mathrm{O}$, or by flash chromatography on silica gel with ethyl acetate/hexane mixtures. Yields are given in Table 2. Physical, spectroscopic, and analytical data, as well as literature references of known compounds are given in the Supporting Information.

Supporting Information (see footnote on the first page of this article).

\section{Acknowledgments}

Financial support from the Ministerio de Ciencia e Innovación (MICINN) of Spain (Project Nos. CTQ2007-65218, CTQ2011-24165, Consolider Ingenio 2010 CSD2007-00006), the Generalitat Valenciana (PROMETEO/2009/039 and FEDER), and the Universidad de Alicante is acknowledged.

[1] T. Hiyama, in Metal-Catalyzed Cross-Coupling Reactions (Eds.: F. Diederich, P. J. Stang), Wiley-VCH, Weinheim, 1998, pp. 421-453.

[2] S. E. Denmark, M. H. Ober, Aldrichimica Acta 2003, 36, 75-85.

[3] Y. Nakao, T. Hiyama, Chem. Soc. Rev. 2011, 40, 4893-4901.

[4] Y. Hatanaka, T. Hiyama, J. Org. Chem. 1988, 53, 918-920.

[5] T. Hiyama, Y. Hatanaka, Pure Appl. Chem. 1994, 66, 1471-1478.

[6] S. Rendler, M. Oestreich, Synthesis 2005, 1727-1747.

[7] J. A. Deiters, R. R. Holmes, J. Am. Chem. Soc. 1990, 112, 71977202.

[8] M. S. Gordon, M. T. Carrol, L. P. Davis, L. W. Burggraf, J. Phys. Chem. 1990, 94, 8125-8128.

[9] A. R. Hajipour, F. Rafiee, Appl. Organometal. Chem. 2013, 27, 412418.

[10] M. E. Mowery, P. DeShong, J. Org. Chem. 1999, 64, 3266-3270.

[11] P. DeShong, C. J. Handy, M. E. Mowery, Pure Appl. Chem. 2000, 72, 1655-1658.

[12] C. J. Handy, A. S. Manoso, W. T. McElroy, W. M. Seganish, P. DeShong, Tetrahedron 2005, 61, 12201-12225.

[13] M. Murata, R. Shimazaki, S. Watanabe, Y. Masuda, Synthesis 2001, 2231-2233.

[14] C. Wolf, R. Lerebours, Org. Lett. 2004, 6, 1147-1150.

[15] H. F. Sore, W. R. J. D. Galloway, D. R. Spring, Chem. Soc. Rev. 2012, 41, 1845-1866.

[16] H. M. Lee, S. P. Nolan, Org. Lett. 2000, 2, 2053-2055.

[17] C. Dash, M. M. Shaikh, P. Ghosh, Eur. J. Inorg. Chem. 2009, 16081618.

[18] X. Zhang, Q. Xia, W. Chen, Dalton Trans. 2009, 7045-7054.

[19] I. Peñafiel, I. M. Pastor, M. Yus, M. A. Esteruelas, M. Oliván, E. Oñate, Eur. J. Org. Chem. 2011, 7174-7181.

[20] I. Peñafiel, I. M. Pastor, M. Yus, Eur. J. Org. Chem. 2013, 14791484.

[21] B. Inés, R. SanMartin, F. Churruca, E. Domínguez, M. K. Urtiaga, M. I. Arriortua, Organometallics 2008, 27, 2833-2839.

[22] E. Alacid, C. Nájera, Adv. Synth. Catal. 2006, 348, 945-952.

[23] D. A. Alonso, C. Nájera, Chem. Soc. Rev. 2010, 39, 2891-2902.
[24] D. Srimani, S. Sawoo, A. Sarkar, Org. Lett. 2007, 9, 3639-3642.

[25] B. C. Ranu, R. Dey, K. Chattopadhyay, Tetrahedron Lett. 2008, 49, 3430-3432

[26] S. B. Park, H. Alper, Org. Lett. 2003, 5, 3209-3212.

[27] L. Bénisvy, J.-C. Chottard, J. Marrot, Y. Li, Eur. J. Inorg. Chem. 2005, 999-1002.

[28] M. S. Saraiva, S. Quintal, F. C. M. Portugal, T. A. Lopes, V. Félix, J. M. F. Nogueira, M. Meireles, M. G. B. Drew, M. J. Calhorda, J. Organomet. Chem. 2008, 693, 3411-3418.

[29] G. Zhang, R. Zong, H.-W. Tseng, R. P. Thummel, Inorg. Chem. 2008, 47, 990-998.

[30] D. A. Krogstad, A. Guerriero, A. Ienco, G. Manca, M. Peruzzini, G. Reginato, L. Gonsalvi, Organometallics 2011, 30, 6292-6302.

[31] C. Zhou, J. Wang, L. Li, R. Wang, M. Hong, Green Chem. 2011, 13, 2100-2106.

[32] R. Torregrosa, I. M. Pastor, M. Yus, Tetrahedron 2005, 61, 11148 11155.

[33] R. Torregrosa, I. M. Pastor, M. Yus, Tetrahedron 2007, 63, 947-952.

[34] a) L. Larhed, C. Moberg, A. Hallberg, Acc. Chem. Res. 2002, 35 717-727; b) C. O. Kappe, B. Pieber, D. Dallinger, Angew. Chem 2013, 125, 1124-1130; Angew. Chem. Int. Ed. 2013, 52, 1088-1094.

[35] A. Guijarro, M. de la Viuda, R. Torregrosa, I. Peñafiel, I. M. Pastor, M. Yus, C. Nájera, Arkivoc 2011, (v), 12-22.

[36] a) J. J. Chen, T. C. Nugent, C. V. Lu, S. Kondapally, P. Giannousis, Y. Wang, J. T. Wilmot, Org. Process Res. Dev. 2003, 7, 313-317; b) V. K. Aggarwal, A. C. Staubitz, M. Owen, Org. Process Res. Dev. 2006, 10, 64-69; c) L. Veum, S. R. M. Pereira, J. C. van der Waal, U. Hanefeld, Eur. J. Org. Chem. 2006, 1664-1671; d) J. T. Kuethe, D. M. Tellers, S. A. Weissman, N. Yasuda, Org. Process Res. Dev. 2009, 13, 471-477; e) J. Mendiola, S. García-Cerrada, Ó. de Frutos, M. L. de la Puente, R. L. Gu, V. V. Khau, Org. Process Res. Dev. 2009, 13, 292-296; f) L. Massari, L. Panelli, M. Hughes, F. Stazi, W. Maton, P. Westerduin, F. Scaravelli, S. Bacchi, Org. Process Res. Dev. 2010, 14, 1364-1372; g) C. Mateos, J. Mendiola, M. Carpintero, J. M. Mínguez, Org. Lett. 2010, 12, 4924-4927; h) B. Mathiessen, A. T. I. Jensen, F. Zhuravlev, Chem. Eur. J. 2011, 17, 7796-7805; i) K. Nishimura, M. Kinugawa, Org. Process Res. Dev. 2012, 16, 225231; j) I. Peñafiel, I. M. Pastor, M. Yus, Eur. J. Org. Chem. 2012, 3151-3156; k) I. Peñafiel, I. M. Pastor, M. Yus, M. A. Esteruelas, M. Oliván, Organometallics 2012, 31, 6154-6161.

[37] M. L. Clarke, Adv. Synth. Catal. 2005, 347, 303-307.

[38] In Figure 4: If the lines run in parallel, there is no interaction between the two parameters, but if they divert, then there is an interaction.

[39] The reaction between 4-bromoanisole and trimethoxy(phenyl)silane under the best reaction conditions but in the absence of $\mathbf{L 1}$ gave the coupling product in $56 \%$ yield, calculated by GLC analysis employing tridecane as internal standard.

[40] The temperature was controlled in one experiment by an externa probe, being in the range of 92 to $97^{\circ} \mathrm{C}$.

Received: ((will be filled in by the editorial staff)) Published online: ((will be filled in by the editorial staff)) 


\section{Entry for the Table of Contents}

Hydroxy- and amino-functionalized imidazoles in combination with palladium acetate are considered to find an efficient and robust catalyst for the fluorine-free Hiyama reaction employing microwave irradiation. The optimal conditions and catalytic system are studied, and then applied to couple different aryl halides with aryl siloxanes.

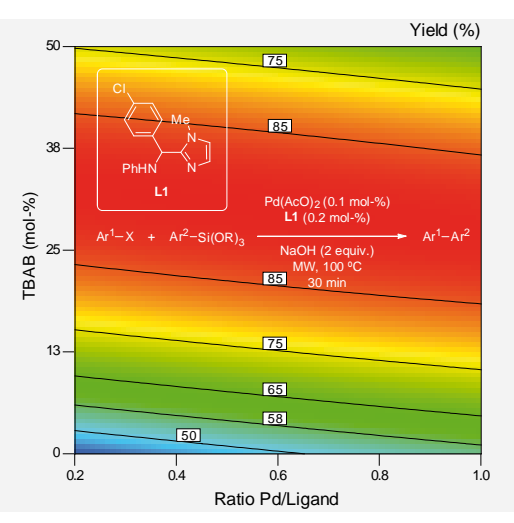

Imidazole Ligands

Regina Martínez, Isidro M. Pastor* and Miguel Yus*....... Page No. Page No.

1,2-Functionalized Imidazoles as Palladium Ligands: Efficient and Robust Catalytic System for the Fluorine-Free Hiyama Reaction

Keywords: Palladium / Organosilane / Hiyama reaction / Imidazole / Biaryls 